\title{
Experienci(a)çóes de reconhecimento e de cuidado no cotidiano de homens idosos rurais
}

\section{| ${ }^{1}$ Andreia Burille, ${ }^{2}$ Tatiana Engel Gerhardt |}

Resumo: Ao envelhecer, os homens se deparam com uma dualidade de exigências: as sociais e as de saúde. Nessa vivência, as relaçóes sociais podem contribuir para situaçôes de cuidado ou de sofrimento. Pesquisa qualitativa, realizada em uma comunidade rural de um município do Vale da Luz/RS. As informaçōes foram produzidas entre janeiro e setembro de 2016, por meio das histórias orais temáticas narradas por dez homens idosos em situaçáo de adoecimento crônico e da composição de diários de campo. A análise buscou referências nas matrizes de Reconhecimento propostas por Honneth. Evidenciou-se que o reconhecimento pelo amor atua como modulador do cuidado biológico nas condiçóes crônicas, mas gera sofrimento ao marcar a invulnerabilidade e a autossuficiência parcial no envelhecimento. No reconhecer pelo direito, enfatizaram-se a aposentadoria e o acesso aos serviços de saúde. As identidades - colono, trabalhador e alemão - constituíram categorias de estima e de solidariedade, sobretudo em situaçóes de adoecimento. As relaçóes mostraram-se aliadas no cuidado, mas ao distanciarem os homens do modelo de masculinidade ou ao depreciarem escolhas, acarretaram sofrimento.

> Palavras-chave: saúde do idoso; saúde do homem; população rural; Saúde Coletiva.
1 Saúde Coletiva, Universidade Federal do Rio Grande do Sul. Porto Alegre-RS, Brasil (andreaburille@gmail.com) ORCID: 0000-0003-0703-4871

2 Saúde Coletiva, Universidade Federal do Rio Grande do Sul. Porto Alegre-RS, Brasil (tatiana. gerhardt@ufrgs.br). ORCID: 0000-0001-8707-6347
Recebido em: 21/07/2017 Revisado em: 29/04/2018 Aprovado em: 22/06/2018 


\section{Introdução}

As lógicas que norteiam parte significativa das práticas de atenção em saúde embasadas no acúmulo de saberes sobre as etiologias, os tratamentos e os fluxos de assistência e isoladas de abordagens que valorizem os contextos de vida têm se mostrado insuficientes para balizar as práticas de cuidado no ideário da Integralidade (BURILLE; GERHARDT, 2016). Considerando-se os dizeres de Canguilhem (2009, p. 182), que "[...] existe uma medicina porque há homens que se sentem enfermos e não porque existem médicos é que os homens vêm a inteirar-se, por meio deles, de que estão enfermos", estudos que tencionam apreender as relaçôes sociais e as repercussóes na saúde e no adoecimento têm ofertado ferramentas indispensáveis para que os profissionais possam reconhecer os saberes da experiência não mais como algo sem valor ou pouco importante na clínica, mas como polo de conhecimento e de riquezas (CYRINO, 2009).

A análise das relaçóes sociais permite rever o modelo de saúde-doença, deslocando-o da visão restrita para a perspectiva ampliada e mobilizadora que o concebe no cuidado (LACERDA; MARTINS, 2013). O apoio social - tangível e intangível - que as pessoas oferecem e recebem tem sido abordado em diversas pesquisas como potente no enfrentamento das adversidades da vida, como a pobreza e os adoecimentos. Nessas condições, os bens materiais e simbólicos colocados em circulação podem frutificar de relaçóes familiares, de vizinhança, de pertença à comunidade e de ações do Estado (GERHARDT, 2006; PORTUGAL, 2005, 2007; PIGNATTI et al., 2011; RUIZ; GERHARDT, 2015). Portanto, em sua complexidade mosaica (MINAYO, 2012), o cuidado pode ser construído em ações cotidianas, assumidas em polifonia, por múltiplos e potenciais agentes.

Olhar para o que circula nas interaçôes sociais se revela fundamental para a compreensão acerca dos limites e das possibilidades das relaçóes na produção do cuidado em saúde, à medida que podem (re) produzir respostas complexas ao viver - isto é, com diferentes revides (GOTTLIEB, 1985; SAMAJA, 2000; LACERDA; MARTINS, 2013). Todavia, cabe considerar que das relaçôes não somente encontros produtores de cuidado fluem, mas também relações estressoras, que alimentam o sofrimento. Pode ocorrer também que as expectativas nas relaçôes, e em cada lócus, não andem ao mesmo passo e na mesma direção (GERHARDT et al., 2009, 2011), logo, é imprescindível não perder de vista que "nem tudo que cai na rede é 
peixe" - ou em outras palavras, que nem tudo que é posto em circulação com boa intencionalidade é assim percebido.

No envelhecer, os homens enfrentam desafios particulares, ao lidar com a dualidade de exigências - as sociais e as de saúde. Mesmo os que desfrutaram do status de bem-sucedidos nos parâmetros do modelo hegemônico de masculinidade (assim nomeado) por agregar atitudes, valores e expectativas esperadas dos homens num plano mais geral nas sociedades ocidentais (CONNELL, 1995a, 1995b; CONNEL; MESSERSCHMIDT, 2013; GOMES et al., 2007; GOMES, 2011) experienciarão algumas dificuldades de manutenção de seu padrão. Sob a égide de determinantes físicos, de orientação para o trabalho, de independência e de poder, os homens idosos passam a conviver com a antítese de tais eixos estruturantes: declínio da força física e saída do mercado de trabalho, com a aposentadoria, os adoecimentos crônicos e a progressiva dependência de terceiros (KILMARTIN, 2002; RIBEIRO, 2010).

Em um estudo que envolveu homens rurais, Burille e Gerhardt (2014) observaram que a dificuldade em atender às expectativas da masculinidade hegemônica repercutia na forma de encarar o adoecimento crônico, desenhando um cenário em que a doença em si não era determinante, mas sim o estar velho. No espaço rural, o adoecimento crônico e as dificuldades para o trabalho - o qual, por suas características produtivas, demanda força física e resistência - operavam como condiçóes marcadoras do envelhecimento. Esse desencontro entre o que se atende e o que se espera permitiu às pesquisadoras compreender as escolhas de não se cuidar ou de correr riscos como uma tentativa de mostrar que o envelhecimento era apenas numérico.

Meneghel et al. (2012) e Pinto et al. (2012) apontam que o potencial polivalente das construçóes sociais sobrepostas aos homens, além de dificultar a busca por cuidado, pode atuar negativamente no vivenciar o envelhecimento. A alienação sobre o corpo, a negação de direitos, a degradação e a ofensa constituem formas de denegação (HONNETH, 2003) não raramente detectadas nesse ciclo de vida, que podem ser alimentadas a partir do adoecimento crônico e das dificuldades laborais, reafirmando assim as incompatibilidades em atender às expectativas do modelo de masculinidade hegemônico e produzindo sofrimento. No entanto, no plano das relaçôes sociais cotidianas, há açôes produtoras de reconhecimento - no amor, na igualdade de direitos e no reconhecimento das singularidades e na estima - capazes de atuar num processo de ressignificação do ser homem, fomentando cuidado. 
Nesse panorama, tem-se claro que o envelhecer não necessariamente vem em simbiose com o adoecimento crônico e com as incapacidades, e que nem todos os idosos ao explicitar tais condiçôes sucumbirão a elas. Ademais, como aduzem Py e Scharfstein (2001, p. 117), “[...] há pessoas que envelhecem bem e outras envelhecem mal”, afinal de contas, portar uma doença crônica não significa ausência de saúde. Contudo, dados epidemiológicos demonstram que o envelhecimento acompanhado pelo adoecimento crônico tem grande magnitude no contexto brasileiro, desvelandose tão significativo quanto o conhecimento de perfis e a qualificação das condiçôes de vida, ao se reconhecer as estratégias e as reaçôes que manifestam os idosos diante das transformaçôes vivenciadas (DOLL, 2011).

Com esses apontamentos, pressupóe-se que o envelhecimento masculino no espaço rural, ao contar com as condiçóes marcadoras "adoecimento crônico" e "dificuldades para desempenhar o trabalho na lavoura", pode ser vivenciado de madeira dinâmica e distinta, conforme a masculinidade e a valoração social podem ser ameaçadas pela incompatibilidade de alcance das prescriçóes do modelo hegemônico. Nesse contexto, as relaçóes sociais podem contribuir com a vivência de cuidado na ressignificação do "ser homem", a partir da produção de reconhecimentos no amor, no direito e na solidariedade (HONNTEH, 2003) - ou de sofrimento, pela não percepção do reconhecer (-se) ou da fragilidade. Assim, com vistas a promover materialidade a essas reflexôes, delineia-se a análise das relaçóes sociais estabelecidas no vivenciar o envelhecimento e da situação de adoecimento crônico entre homens residentes em um meio rural.

\section{Metodologia}

As informações compartilhadas integram uma pesquisa de abordagem qualitativa que originou uma tese defendida em meados de 2017. No universo das abordagens qualitativas, recorreu-se à etnometodologia, em que se prioriza a "observação direta e a investigação detalhada dos fatos, no lugar em que ocorrem, com a finalidade de produzir uma descrição minuciosa e densa das pessoas, de suas relaçôes e de sua cultura" (MINAYO, 2014, p. 149). O trabalho de campo decorreu entre janeiro e setembro de 2016, em uma comunidade rural localizada em um pequeno município do Vale da Luz, no Estado do Rio Grande do Sul (RS), escolhido por agregar características gerais dos municípios da região, quais sejam: número pequeno de 
moradores; percentuais de idosos acima da média do Estado; parcela significativa de moradores no meio rural; e ruralização, em que a vida urbana se diferencia, mas incorpora-se e guia-se pelo rural.

Das 11 comunidades rurais do município, selecionou-se Teichland (nome fictício - no dialeto local significa "terra de lagoa"), por contabilizar o maior número de idosos. Situada num terreno acidentado, a dez quilômetros distante da área urbana, na comunidade residem 392 moradores, dos quais mais da metade tem 60 anos de idade ou mais. Constituída de pequenas propriedades, as famílias que ali residem trabalham em cadeia de subsistência e em sistema de integração de leite, de aves e de suínos. Com fortes traços da cultura alemã, os moradores preservam os costumes, como casas em moldes enxaimel, Kerbs - festas regadas por linguiça, cuca e bandinha alemã, iniciadas pela "Polonaise", uma dança de integração social e cultural -, e as festividades de Páscoa, "Osternfest", trazidas por antepassados que se estabeleceram na região em meados do século XIX. A comunicação ocorre pelo dialeto local, e a língua portuguesa se expressa, por alguns, com dificuldade, apenas para conversar com "os de fora".

Contribuíram para a geração de informaçôes dez homens com 60 anos ou mais, que relataram autorreferência de doença cardiovascular, escolhida em virtude da magnitude na região, podendo ser acompanhada - ou não - de outra condição crônica. Abarcaram também critérios de elegibilidade para participar da pesquisa: homens que tinham (ou tiveram) como ocupação laboral principal a agricultura; que soubessem se comunicar em português; e que residissem na comunidade. Embora houvesse 22 homens que atendessem aos critérios elencados, o número de participantes seguiu o critério de saturação de informaçôes, ou seja, quando já há informaçôes ricas e suficientes para responder de forma coletiva aos objetivos propostos, como descreve Minayo (2012, p. 622), “[...] embora pessoal, toda vivência tem como suporte os ingredientes do coletivo em que o sujeito vive e as condiçôes em que ela ocorre".

A composição dos diários de campo, a compilação, a produção e a análise de fotografias e a construção de histórias orais temáticas, definidas por Meihy e Holanda (2007) como a narrativa que entrecruza interesses, relaçôes e memória, deram movimento aos nove meses de idas e vindas à comunidade. As narrativas foram transcritas, textualizadas, transcriadas e validadas pelos entrevistados. Nelas, compôs-se a triangulação por intermédio de entrevistas, de fotografias e 
de observaçôes registradas em diários de campo. As informaçôes restantes foram ordenadas com o auxílio da técnica de análise temática proposta por Minayo (2012) e analisadas conforme as categorias analíticas predefinidas pelo estudo-gênero - a saber, uma categoria de análise fundamentada por Joan Scott - e pela estrutura de relaçóes sociais de reconhecimento de Honneth (2003).

Sobre as consideraçóes bioéticas, a proposta de pesquisa foi aprovada pelo Comitê de Ética em Pesquisa (CEP) da Universidade Federal do Rio Grande do Sul (UFRGS), sob o no 1397024. As prerrogativas da Resolução no 466, de 12 de dezembro de 2012, do Conselho Nacional de Saúde (CNS) (BRASIL, 2012) foram seguidas. Para assegurar a preservação da identidade dos participantes, seus nomes foram substituídos.

\section{Resultados e Discussão}

\section{Aproximando-se de Honneth para analisar as relaçóes e apreender o Reconhecimento}

Para "enxergar" experiências de reconhecimento no envelhecimento masculino no meio rural foi preciso, antes de tudo, desvendar as relaçóes e o que nelas circulava e o que produzia sofrimento e cuidado. Nessa perspectiva, assumiu-se o cuidado como resposta social não apenas ao adoecimento, mas aos modos de vida saudáveis, dependentes da qualidade das relaçóes - isto é, do que circula na forma de bens e do que trazem embutidos (MARTINS, 2011). Como matriz teórica, elegeu-se Luta por Reconhecimento: a gramática moral dos conflitos sociais, obra traduzida e publicada no Brasil, em 2003, de autoria de Axel Honneth, filósofo e sociólogo alemão, pertencente ao Departamento de Filosofia da Universidade de Frankfurt. No prisma da Teoria Crítica, o reconhecimento preconizado por Honneth (2003) revela um conjunto de relaçôes carregadas de bens simbólicos e materiais guiados por normas e por expectativas que unem as pessoas num projeto de sociabilidade. Nas interaçóes, ao se sentir reconhecido, o indivíduo passa a se perceber como sujeito com valores e com singularidades, e, por sua vez, passa a notar o outro em seu valor enquanto sujeito.

Em uma leitura dos escritos de Hegel, Honneth (2003) depreendeu a dupla tipologia tripartite de relaçôes intersubjetivas e interligadas, deixando à mão açôes de desrespeito que geram a denegação, para, num segundo plano, direcionar-se para 
a construção teórica de uma matriz de reconhecimento, situando-a em padrôes resultantes em autoconfiança, em autorrespeito e em autoestima. Para o sociólogo, o reconhecimento está imbricado com a socialização e se processa em diferentes esferas de reprodução da vida social, permeando o espaço doméstico e o das relaçóes primárias, no que concerne à esfera do amor, estendendo-se à vida pública, nas esferas do direito e da solidariedade.

\section{Reconhecimento no Amor}

O reconhecimento pelo amor compóe a primeira matriz de Honneth (2003). Nela residem as relaçóes alimentadas por vínculos afetivos e por reciprocidades (família, amigos, vizinhos). Surgem a afeição e o encorajamento, que potencializam a autoconfiança, que, num segundo momento, estende-se às demais relaçóes que os sujeitos vão tecendo em seu percurso de vida. No decorrer da pesquisa, diversas experiências suscitaram essa forma de reconhecimento, dentre elas, o cuidado desencadeado pela família - especialmente pelas esposas e pelos filhos -, também documentado por outros trabalhos que conferem destaque às mulheres, na condição de mães, de filhas, de esposas (BARSAGLINI; CANESQUI, 2010; KOLLING, 2010; SOUZA, 2011; BURILLE, GERHARDT, 2016). Nesse ponto de vista, importa ponderar que os dez entrevistados eram casados e tinham filhos. $\mathrm{O}$ amor e o respeito recebidos - e, ao mesmo tempo, retribuídos - apareceram nos relatos como forma de superação das adversidades cotidianas, como as perdas nas lavouras pelas intempéries climáticas ou o sofrimento pelo adoecimento crônico. Para ilustrar, fragmentos dos diários de campo e das entrevistas:

[...] encontro a esposa de Edvald na varanda, passando roupa. Pergunto por que ela estava passando as roupas "de ficar em casa", e ela me responde com um sorriso: Edvald gosta de estar sempre impecável, faço isso para ele se sentir bem, náo é!? [...] (Diário de Campo, 16 de abril de 2016).

[...] quando eu desmaiei, o meu neto me dava os comprimidos, eu andava meio esquecido, ele vinha quatro vezes por dia, debaixo de sol e de chuva, fazia um chá e me dava os comprimidos, ele dizia: vô, tu cuidaste de mim, agora eu te cuido (Hilário, 85 anos).

Averiguou-se que os entrevistados que vivenciavam relaçóes familiares estreitas e com maior convivência - e a priori, harmoniosas - desfrutavam de certo "vigiar", o que interferia positivamente no cuidado das condiçôes crônicas. Nesse grupo, em que puderam ser alocados sete dos dez entrevistados, o cuidado aparecia como uma ação 
assumida pela família, diante das necessidades apresentadas. Se, por um lado, esse cuidar podia instigar que as condiçôes crônicas agudizassem menos, por outro, ao se considerar as normativas do modelo hegemônico de masculinidade, gerava sofrimento, por atentar o ideário de invulnerabilidade e por marcar que a autossuficiência pode ser parcial - em especial, pelas limitaçóes no trabalho rural. Como exemplo de como o reconhecimento pelo amor pode produzir sofrimento, cita-se a história de Werno, de 75 anos, que após cirurgia, queria plantar uma lavoura de feijão:

[...] Encontro a agente comunitária de saúde que também estava a caminho de sua casa. No caminho, ela conta que voltando da cirurgia, os filhos de Werno combinaram de dizer que estavam ocupados com outros afazeres para não irem lavrar um pedaço de terra que o pai havia pedido, pois se fossem, no outro dia, ele estaria lá fazendo esforço, proibido por noventa dias pelo médico. Dessa forma, ao dizerem-se ocupados, forçariam ele ao repouso, para sua recuperação. No entanto, Werno, diante das impossibilidades dos filhos, foi até o vizinho mais próximo e solicitou que fizesse o serviço - que iria pagar quando recebesse a aposentadoria. $\mathrm{O}$ vizinho, por conhecer a situação de saúde, desconfiou que havia alguma coisa de errado, e foi até sua casa conversar com a esposa, que contou da combinação dos filhos. Ao tomarem conhecimento do ocorrido, os filhos foram conversar com o pai, que mesmo contrariado, deu sua palavra que iria se cuidar nos noventa dias (Diário de Campo, 12 de junho de 2016).

Enfatiza-se, por conseguinte, que o cuidado com a saúde esteve presente no cotidiano dos entrevistados mais pela relação com o outro, do que por si. Dos entrevistados, três apenas o assumiram como prática em que se colocavam como protagonistas. Ildo, 69 anos, após perder os dois filhos por suicídio, afirmava que se cuidar era necessário para não ficar pelas "valetas". Liro, 60 anos, relatava consciência de que precisava fazer por si após o acidente que sofreu, ao voltar, de bicicleta, para casa, alcoolizado. Na época, confessou ter causado muitos transtornos à família, e seu filho acabara se estressando com as demandas: "era um estorvo". Já Sinésio, 63 anos, parecia ter encontrado equilíbrio nas relaçôes de cuidado pela ressignificação da masculinidade. Ao realizar curativos diários decorrentes de úlcera venosa, afirmou que o cuidado fora assumido pelo desejo de permanecer entre os seus, e, acima de tudo, de estar ao lado da esposa, honrando os votos feitos no casamento. Assim, reiterava as expectativas da masculinidade hegemônica pela palavra a ser cumprida.

Pelas lentes do amor, os homens salientaram o cuidado recebido, mas também por eles ofertado à família e aos filhos, pela preocupação com o trabalho e com o prover das necessidades e com o bem-estar para a proteção, o que incorpora outra via de inteligibilidade de cuidar que não é assegurada nos discursos tradicionais 
em saúde, mais próximos das representaçôes de feminilidade. Por essa via, pôde-se inferir que o cuidar do outro é também cuidar de si, num ciclo embasado pela troca de bens materiais e imateriais, repletos de simbolismo e de afetividade. De acordo com o que lecionam Lago e Muller (2010), esses achados rompem com a noção de que os homens náo cuidam nem de si, nem dos outros. Há um cuidado exercido pelos homens - talvez, não tão próximo do que preconizam os serviços de saúde ou do assumido pelas mulheres, mas calcado em estruturas simbólico-culturais que balizam o modelo de masculinidade "idealizado" em sociedades ocidentais.

\section{Reconhecimento pelo Direito}

Em sua teoria, Honneth (2003) classifica como segunda matriz de reconhecimento o direito, não essencialmente o circunscrito ao âmbito jurídico, mas o da possibilidade de desfrutar das oportunidades ao outro concedidas e o da autonomia para a tomada de decisóes. Nessa esfera se processam as interaçóes em busca do respeito social, regidas pelo autorrespeito. Sob essa égide, os entrevistados listaram experiências que se aglutinam em dois pontos de discussão: a aposentadoria e o acesso aos serviços de saúde.

A aposentadoria foi mencionada como uma conquista - em especial, pelas memórias de quando os agricultores não desfrutavam dos mesmos direitos legitimados aos trabalhadores urbanos. Esse resgate histórico reacendeu nos relatos como forma de reconhecimento pelo Estado. O dinheiro era recebido com apreço e fazia diferença nos modos de andar a vida, principalmente para aqueles entrevistados com dificuldades de reprodução material. Decorre dessa relação com o Estado a oportunidade de acessar bens que não eram possíveis quando dependiam da produção agrícola, pois muitos não haviam contado, até se aposentar, com um ganho garantido mensalmente. Até os que desfrutavam de melhores condiçôes de vida a valorizaram, como um merecimento pela vida dedicada ao trabalho.

\footnotetext{
[...] essa geladeira com duas portinhas eu comprei agora. Também comprei dois terneiros para engordar. Com a aposentadoria dá para fazer dívida (risos). Todo mês, até o governo não quebrar, tem o dinheirinho lá. Antes não podia sair comprando, não se sabia se podia pagar e não tem coisa mais feia para um homem de família que ficar com o nome sujo, o que vão dizer? (Ernesto, 76 anos).
}

A aposentadoria também sintetiza uma alternativa de sanar a lacuna do Estado diante das medicações para o tratamento das condiçóes crônicas. Muitos 
entrevistados, pela especificidade clínica ou pela condição individual de tolerância, diante da prescrição de medicamentos que não constavam na Relação Nacional de Medicamentos distribuídos pelo Sistema Único de Saúde (SUS), utilizavam o benefício, que inclusive era acionado para o pagamento de exames cuja espera pelo sistema público seria incompatível. Com isso, um bem que deveria ser empregado para promover qualidade de vida na velhice serve aos entrevistados como alternativa, diante dos entraves crônicos do SUS. No cenário da pesquisa, assim como evidenciado por outros estudos, a aposentadoria gera visibilidades e atua na condição de mantenedora da própria sociedade rural e da permanência das pessoas no campo (TONEZER, 2009; OLIVEIRA, 2013; RUIZ; GERHARDT 2015; BURILLE; GERHARDT, 2016).

Em contrapartida, nem só positividades são colocadas em circulação pela aposentadoria. Ao se estender às mulheres, acarreta mudanças relacionais: se elas passam a desfrutar da autonomia - antes cerceada - de ter determinado valor monetário em seu nome, os homens precisam, no envelhecimento, efetuar negociaçóes, posto que a reprodução material delas (as esposas) não mais depende dos ganhos da lavoura, por eles administrados. O ganho monetário também facilita a especulação e os pedidos de empréstimos consignados, que demandam aos idosos um comprometimento importante da renda - como revelou Werno, 75 anos, que ao ser indicado para avalizar o genro, disse ter ido ao banco e solicitado aos atendentes que parassem de sugerir essa modalidade, pois geravam desavenças familiares que o deixavam nervoso e "atacavam a pressão".

$\mathrm{Na}$ visão de Heck (2004), as mulheres, particularmente ao conquistar a aposentadoria rural, buscam reforçar as relaçóes sociais, protagonizando nessa experiência a valorização da identidade com uma nova possibilidade de envelhecer, por meio da motivação e da participação social. Mesmo que a aposentadoria rural desempenhe papel crucial na ação construtora de cidadania e de acesso aos bens materiais (TONEZER, 2009; RUIZ; GERHARDT, 2015), para os homens, embora necessária, não é tão apreciada, visto que seu dinheiro não advém do trabalho componente importante da identidade masculina. Doll (2011) arremata que, por configurar um dos pilares da identidade masculina, a saída do mundo do trabalho faz com que muitos homens, quando idosos, encarem dificuldades em constituir sentido à vida, predispondo-se ao isolamento e aos sintomas depressivos, sobretudo se a saída for decorrente de limitaçôes desencadeadas pelo adoecimento crônico. 
A garantia de acesso aos serviços de saúde - validada pelas condicionalidades programadas aos idosos - constitui outra forma de reconhecimento pelo direito. Todavia, nos relatos, evidenciou-se que isso não parece ser suficiente para produzir cuidado, sobretudo se as práticas profissionais não levarem em conta os contextos geracionais, de gênero e de cenário de vida. Embora não se justifique no cotidiano, frequentemente os profissionais são tomados pela lógica produtivista - em que números são indicadores de qualidade - e por evidências científicas homogeneizantes que colocam pessoas diferentes nas mesmas condições. Por conseguinte, acontecem desencontros, entre quem espera o cuidado e quem acha que está oferecendo. Para alimentar essa discussão, tem-se a narrativa de Ildo, abordado após a consulta com a nutricionista da unidade de saúde.

[...] em tom de indignação, me responde que não iria mais, que ela havia repreendido por consumir banha de porco e orientado a substituição pelo azeite. Que durante seus sessenta e nove anos sempre havia se alimentado com banha, que seus antepassados consumiam e que, além do mais, o azeite era produto para rico. Não satisfeito, disse que a mesma havia recomendado comer peixes que nem tinham no mercado e um monte de comida de passarinho (sementes). Onde já se viu, um homem comer isso?! Desapontado, verbalizou que a profissional não entendia sua condição de vida (Diário de Campo, 23 de abril de 2016).

Zoboli e Junges (2016), ao discorrerem sobre os encontros entre profissionais e usuários, destacaram que a excelência do cuidado, por imperativo ético, não pode ocorrer se os olhares focarem apenas nas condiçôes clínicas. Para os pesquisadores, há que se criar espaços de interesse, de escuta e de atenção que ampliem e que compaginem a análise dos determinantes sociais em saúde, contextualizando espaços e tempos de vida. Riquinho e Gerhardt (2010) sinalizaram que tão essencial quanto agricultores familiares serem reconhecidos como portadores - ou não - de uma patologia é serem vistos como pessoas que dependem do trabalho na terra e têm nele sua marca. Nesse ensejo, Ruiz et al. (2016) apontaram a mediação como estratégia para o reconhecimento das singularidades, um caminho potente nas práticas de saúde. Por outro lado, quando o encontro entre profissional e usuário ocorre em sincronia, há produção de reconhecimentos que se refletem no cuidado: Selino, 60 anos, como forma de agradecimento ao empenho e à sensibilidade do cirurgiáo vascular que o atendia pelo SUS, preparava, a cada consulta, uma caixa de frutas produzidas em sua propriedade. Nela, punha as frutas mais bonitas, apanhadas no orvalho do amanhecer. Em suas palavras, a postura acolhedora e interessada 
do profissional fazia com que se sentisse reconhecido como pessoa de valor, e a oferta das frutas consistia em uma forma de retribuir com o que, dentro de suas possibilidades, produzia de melhor.

\section{Reconhecimento pela Estima e pela Solidariedade}

O reconhecimento pela estima social e pela solidariedade pauta a terceira matriz tecida por Honneth (2003). Nela constam as categorias reputação e prestígio, que interferem na autoestima que o indivíduo goza socialmente quanto às suas realizaçóes. Distintamente do reconhecimento jurídico - que remete à igualdade dos sujeitos e às propriedades que são universais -, essa forma de reconhecimento retrata as particularidades. Ademais, guarda estreita relação com o bem-estar social, com forte ligação com o mundo do trabalho. De acordo com o que assevera Ruiz (2013), o trabalho no meio rural simboliza uma das janelas de interface com o exterior que propicia a possibilidade de vivenciar identidades que avalizam o prestígio. No plano relacional, mesmo no envelhecimento, valida a sociabilidade e a honra de ser alguém que produz e que contribui para a sociedade. Somente estão liberados aqueles que não podem exercê-lo por restriçôes impostas pelo adoecimento, e mesmo nessas condições, muitos insistem em prosseguir. Representam a situação, por exemplo, Liro, que caminhava com muletas e ainda assim cortava o pasto e auxiliava na ordenha do leite, e Sinésio, que improvisava um curativo com sacolas plásticas para executar as atividades na propriedade. Nesse espaço de vida, o trabalho é polissêmico: trabalha-se porque se tem saúde; tem-se saúde porque se trabalha.

As falas dos entrevistados expressam que a dimensão do trabalho extrapola a reprodução material, posto que dá sentido ao viver, consolida projetos de vida e transmite valores. Em comum, os idosos frisaram a imagética de serem homens de bem - o que Guido traduziu como um homem que cuidou da família, que honrou a palavra, que foi solidário na comunidade e que auxiliou projetos coletivos. Como fruto dessa caminhada, relembrou que, ao efetuar um procedimento cirúrgico, Sinésio foi um dos vizinhos que se solidarizou:

[...] ele se ofereceu para, se precisar de ajuda, mandar o empregado dele aqui. Tinha mais pessoas que queriam me ajudar ou me mandavam recado, ou telefone, até pessoas que eu nem me lembrei que se formaram comigo, aí depois ela (filha) saía do serviço, enquanto estava no banco: como está teu pai, como está teu pai? E todos dias vinham, quem pediu, eu nem sei quem é, aquele era amigo, às vezes nem sabiam quem eram, que era me conhecido, perguntavam do pai (Guido, 82 anos). 
O reconhecimento nas situaçóes de adoecimento se concretiza pela solidariedade, que é fomentada pelo pertencimento e pelas relaçôes de dar-receber-retribuir, cultivadas ao longo dos anos, haja vista todos os entrevistados residirem há mais de trinta anos na comunidade. A estima, embora náo se dissocie das relaçôes de solidariedade, pode ser manifestada por outras açôes, como o convite para integrar as reuniôes representativas da comunidade. Três dos dez entrevistados - Sinésio, Edvald e Guido - ocuparam cargos em espaços sociais com gerência, quando mais jovens, e mesmo sem o desejo de ocupá-los novamente, seguiram convidados para as discussóes - o que recebiam com apreço, uma vez que se sentiam valorizados pelos saberes que guardam. Desse modo, entende-se que o reconhecimento pela estima e pela solidariedade representa um cuidado social.

Pignatti et al. (2011), ao confeccionar um estudo com idosos no território rural do Pantanal mato-grossense, elaboraram um cenário que se aproxima do compartilhado por este estudo. As pesquisadoras retrataram que, em vários aspectos da vida, laços de solidariedade, trocas e obrigaçóes parecem reger o apoio social em comunidades rurais. No entanto, nenhum com tanto vigor quanto no que tange à saúde, cujos tipos de apoio mobilizados se influenciam pelo modo de vida rural e moldam significativamente suas representaçôes sobre saúde, doença, trabalho. Seriam essas relaçôes, portanto, expressões em que o bem coletivo se sobrepóe ao individual, capazes de ampliar o senso de comunidade e de coesão.

Outra forma de reconhecimento pela estima que causa efeitos no cuidado de si e da saúde contempla as identidades de "colono" e de ser "alemão". Ao se declarar "colono", o jogo de representaçóes se entremeia entre o que se percebe e o que isso representa na sociedade. Mesmo diante das mudanças que a identidade de "colono" tem experimentado, a escolha em seguir assim identificando-se significa uma aposta no que se viveu, no lugar em que se vive - "o rural é o melhor lugar para se viver” - e no que se produziu para a sociedade. Já a identificação como alemães explicita, conforme o entendimento de Walachai (2009), uma identidade cambiante: identifica-se como brasileiro por ter nascido no Brasil, mas também como alemão, pela cultura que preserva. Há na comunidade, não diferentemente de outros povoados constituídos por imigrantes, influências culturais que separam "os daqui" dos "de fora", como referência aos não pertencentes às famílias locais.

Ao tratar sobre as mudanças na contemporaneidade, Bauman (2005, p. 29) debateu a ideia de identidade nacional como processo político e simbólico 
arraigado à naturalidade e ao nascimento, que, por vezes, sobrepóe-se ao desejo e ao reconhecimento dos indivíduos, ou "[...] nasce com o silenciamento de outros discursos, locais e regionais". Embora saibam da naturalidade brasileira, os entrevistados, ao declararem-se como "alemães", expressaram a liberdade de escolha em um movimento de busca de segurança oferecida pelo pertencimento capaz de assegurar a existência humana decente e madura. Por ela - a identidade de "alemão" - pode-se desfrutar de uma rede de solidariedade, ao mesmo tempo que há liberdade de ser quem se é, mesmo que isso signifique ser reconhecido também por negatividades - como homens introspectivos, rígidos e de poucos amigos.

\section{Consideraçóes finais}

As narrativas colhidas ao longo da pesquisa revelaram a complexidade da vida humana. Embora os entrevistados apresentassem características em comum, alinhadas a priori por critérios de inclusão, e subsequentemente moldadas pelo tecido social e pelas tessituras culturais - representadas pelo valor do trabalho, da palavra e da preservação dos costumes locais (em especial, as tradiçôes alemâs) -, cada história de vida foi permeada por subjetividades. Nesse processo, as relaçôes mostraram-se potentes aliadas no cuidado em saúde, mas ao distanciar os homens dos mandatórios do modelo hegemônico de masculinidade ou ao pôr em circulação juízos de valores depreciativos das escolhas e dos modos de ser, também desencadearam sofrimento. Da itineração ressaltou-se o reconhecimento pelo amor como relevante modulador do cuidado nas condiçôes crônicas, ou em seu sentido biológico, por um "vigiar", ao mesmo tempo que se retratou uma fonte de sofrimento, ao marcar a invulnerabilidade ao adoecimento e a autossuficiência parcial no envelhecimento. Salientou-se também o importante papel do Estado na regulação de ações abusivas direcionadas à aposentadoria, uma vez que pode repercutir não apenas em prejuízos monetários, mas nas relações dos idosos.

Para alimentar práticas profissionais inclusivas e integrais, convida-se à reflexão sobre como estão sendo produzidos os encontros e o que deles pode frutificar. Há ainda que se exercitar o olhar para além dos dados biológicos e se considerar que não se tratam de corpos à frente, mas de pessoas circunscritas em relaçóes e em contextos de vida. Ao fim, pontua-se como possível contribuição do estudo, diante dos escassos referenciais existentes e até mesmo de certa invisibilidade do tema, a inclusão das experiências de saúde e de adoecimentos de homens idosos que residem 
em espaços rurais. Mais do que uma ação de pesquisa, com essa proposta almeja-se produzir reconhecimentos que se reflitam em políticas públicas capazes de acolher singularidades como valor humano. ${ }^{1}$

\section{Referências}

BARSAGLINI, R.; CANESQUI, A. M. O gerenciamento da dieta e da alimentação na condição crônica do diabetes. Saúde e Sociedade. São Paulo: USP, v. 19, p. 919-932, 2010.

BAUMAN, Z Identidade. Trad. Carlos Alberto Medeiros. Rio de Janeiro: J. Zahar, 2005.

BRASIL. Ministério da Saúde. Conselho Nacional de Saúde. Resolução $n^{\circ} 466$, de doze de dezembro de 2012. Aprova as diretrizes e normas regulamentadoras de pesquisas envolvendo seres humanos. DF: CNS, 2012. Disponível em: <http://bvsms.saude.gov.br/bvs/saudelegis/ cns/2013/res0466_12_12_2012.html>.

BURILLE, A.; GERHARDT, T. Doenças crônicas, problemas crônicos: encontros e desencontros com os serviços de saúde em itinerários terapêuticos de homens rurais. Saúde \& Sociedade. São Paulo v. 23, n. 2, p. 664-676, jun. 2014.

. Entre ressacas e marolas: um olhar para os itinerários terapêuticos e redes sociais de homens em situação de adoecimento crônico. In: GERHARDT, T. E. et al. (Org.). Itinerários terapêuticos: integralidade no cuidado, avaliação e formação em saúde. Rio de Janeiro, 2016. v. 1, p. 375-390.

CANGUILHEM, G. O normal e o patológico. 6. ed. Rio de Janeiro: Forense Universitária, 2009.

CONNELL, R. Masculinities. Berkeley: University of California Press, 1995 b.

Políticas da masculinidade. Educação \& Realidade. Porto Alegre, v. 20, n. 2, p. 185-206, $1995 a$.

CONNELL, R. W.; MESSERSCHMIDT, J. W. Masculinidade hegemônica: repensando o conceito. Revista Estudos Feministas. Florianópolis, v. 21, n. 1, p. 241-282, abr. 2013.

CYRINO, A. Da educação sanitária a emergência da inteligência coletiva. In: CYRINO, A. Entre a ciência e a experiência: cartografia do autocuidado no diabetes. São Paulo: Ed. UNESP, 2009, p. 35-52.

DOLL, J. Envelhecimento e trabalho na sociedade contemporânea. In: RIBEIRO, J. A. R.; RIBEIRO, M. (Org.). Redes de pesquisa: trabalho, movimentos sociais e educação. Porto Alegre: Itapuy, 2011, p. 272-277.

GERHARDT, T. E. Itinerários terapêuticos em situaçóes de pobreza: diversidade e pluralidade. Cadernos de Saúde Pública. Rio de Janeiro, v. 22, n. 11, p. 2449-2463, nov. 2006. 
GERHARDT, T. et al. Atores, redes sociais e mediação na saúde, laços e nós em um cotidiano rural. In: PINHEIRO, R.; MARTINS, P. H. (Org.). Usuários, redes sociais, mediaçôes e integralidade em saúde. Rio de Janeiro: CEPESC : IMS-UERJ; Recife: Ed. Universitária UFPE; São Paulo: ABRASCO, 2011, p. 253-270.

- Determinantes sociais e práticas avaliativas de integralidade em saúde: pensando a situação de adoecimento crônico em um contexto rural. In: PINHEIRO, R.; MARTINS, P. H. (Org.). Avaliação em saúde na perspectiva do usuário: abordagem multicêntrica. Rio de Janeiro: CEPESC: IMS-UERJ; Recife: Ed. Universitária UFPE; São Paulo: ABRASCO, 2009, p. 287-98.

GOMES, R.. A sexualidade masculina em foco. In: (Org.). Saúde do homem em debate. Rio de Janeiro: FIOCRUZ, 2011, p. 145-156.

GOMES, R.; NASCIMENTO, E. ARAÚJO, F. Por que os homens buscam menos os serviços de saúde do que as mulheres? As explicaçôes de homens com baixa escolaridade e homens com ensino superior. Cadernos de Saúde Pública. Rio de Janeiro, v. 23, n. 3, p. 565-74, mar. 2007.

GOTTLIEB, B. H. Social networks and social support: an overview of research, practice, and policy implications. Health Education Quarterly. Thousand Oaks, Ca, v. 12, n. 1, p. 5-22, 1985. HECK, R. Percepçáo social de categorias de risco de suicídio em colonos alemães do noroeste do Rio Grande do Sul. Texto Contexto Enfermagem. Florianópolis, v. 13, n. 4, p. 559-567, out./ dez. 2004.

HONNETH, A. Luta por reconhecimento: a gramática moral dos conflitos sociais. Sáo Paulo: Editora 34, 2003.

KILMARTIN, C. The masculine self. 2. ed. New York: McGrawHill, 2002.

KOLLING, M. Diabetic disruption to male gender identity: an anthropological investigation of chronic illness among men in the city of Salvador, northeast, Brazil. 2010. 120 f. Dissertação (Mestrado) - Departamento de Antropologia, Faculdade de Ciências Sociais da Universidade de Copenhagen, Copenhagen, Denmark, 2010.

LACERDA, A.; MARTINS, P. H. A dádiva no trabalho dos agentes comunitários de saúde: a experiência do reconhecimento do amor, do direito e da solidariedade. Realis - Revista de Estudos Antiutilitaristas e Poscoloniais, v. 3, p. 194-213, 2013.

LAGO, M. C. de S.; MÜLLER, R. de C. F. O sujeito universal do cuidado no SUS: gênero, corpo e cuidado com a saúde nas falas de profissionais e usuários do Hospital UniversitárioFlorianópolis, Santa Catarina. In: STREY, M. N.; NOGUEIRA, C.; AZAMBUJA, M. R. (Org.). Gênero \& saúde: diálogos ibero-brasileiros. Porto Alegre: EDIPUCRS, 2010, p. 279-302.

MARTINS. J. de S. A sociabilidade do homem simples: cotidiano e história na modernidade anômala. São Paulo: Contexto, 2011.

MEIHY, J. C.; HOLANDA, F. História oral: como fazer como pensar. São Paulo: Contexto, 2007. 
MENEGHEL, S. et al. Suicídio de idosos sob a perspectiva de gênero. Revista Ciência \& Saúde Coletiva. Rio de Janeiro, v. 17, n. 8, p. 1983-1992, ago. 2012.

MINAYO, M. C.. Análise qualitativa: teoria, passos e fidedignidade. Ciência \& Saúde Coletiva. Rio de Janeiro, v. 17, n. 3, p. 621-626, mar. 2012.

- O desafio do conhecimento: pesquisa qualitativa em saúde. 14. ed. São Paulo: Hucitec, 2014.

OLIVEIRA, A. de. Formas de envelhecer no meio rural: diálogos entre saúde e desenvolvimento. 2013. 120 f. Dissertação (Mestrado em Desenvolvimento Rural) - Universidade Federal do Rio Grande do Sul, Porto Alegre, 2013.

PIGNATTI, M. G.; BARSAGLINI, R. A. SENNA, G. D. Envelhecimento e rede de apoio social em território rural do Pantanal matogrossense. Physis: Revista de Saúde Coletiva. Rio de Janeiro, v. 21, n. 4, p. 1469-1491, dez. 2011.

PINTO, L.; ASSIS, S.; PIRES, T. Mortalidade por suicídio em pessoas com 60 anos ou mais nos municípios brasileiros no período de 1996 a 2007. Revista Ciência \& Saúde Coletiva. Rio de Janeiro, v. 17, n. 8, p. 1963-1972, ago. 2012.

PORTUGAL, S. O que faz mover as redes sociais? Uma análise das normas e dos laços. Revista Crítica de Ciências Sociais. Lisboa, v. 79, p.35-56, dez. 2007.

. Quem tem amigos tem saúde: o papel das redes sociais no acesso aos cuidados de saúde. In: SIMPÓSIO FAMÍLIA, REDES SOCIAIS E SAÚDE, 1., 2005, Hamburgo. Comunicação no simpósio família, redes sociais e saúde. Hamburgo: Instituto de Sociologia de Hamburgo, 2005. p.1-23.

PY, L.; SCHARFSTEIN, E. Caminhos da maturidade: representaçóes do corpo, vivências de afetos e consciência de finitude. In: NERI, A. (Org.). Maturidade e velhice trajetórias individuais e socioculturais. São Paulo: Papirus, 2001, p. 117-150.

RIBEIRO, O. Saúde, masculinidade e envelhecimento: reflexóes sociais numa perspectiva de gênero. In: STREY, M. N.; NOGUEIRA, C.; AZAMBUJA, M. R. (Org.). Gênero \& saúde: diálogos ibero-brasileiros. Porto Alegre: EDIPUCRS, 2010, p. 303-324.

RIQUINHO, D. L.; GERHARDT, T. E. Doença e incapacidade: dimensóes subjetivas e identidade social do trabalhador rural. Saúde e Sociedade. São Paulo: USP, v. 19, n. 2, p. 320332, jun. 2010.

RUIZ, E. Relaçôes sociais nas situaçôes de adoecimento crônico no rural: expressóes de cuidado e de sofrimento na perspectiva da dádiva. 2013. 212 f. Tese (Doutorado em Desenvolvimento Rural) - Faculdade de Ciências Econômicas, Universidade Federal do Rio Grande do Sul, Porto Alegre, 2013. 
RUIZ, E.; GERHARDT, T. O adoecer crônico no rural e o cuidado na forma de respostas do social: apreensóes a partir da Teoria da Dádiva. In: GERHARDT, T. E.; LOPES, M. J. M. (Org.). O Rural e a saúde: compartilhando teoria e método. Porto Alegre: Editora da UFRG, 2015, p. 29-56.

RUIZ, E.; SANTOS, V.; GERHARDT, T. Mediaçôes na atenção à saúde sob a ótica da Teoria da Dádiva: a saúde da populaçáo rural em destaque. Physis: Revista de Saúde Coletiva. Rio de Janeiro, v. 26, n. 3, p. 829-852, set. 2016.

SAMAJA, J. A reprodução social e a saúde: elementos metodológicos sobre a questão das relações entre saúde e condiçóes de vida. Salvador: Casa da Qualidade, 2000.

SOUZA, A. C. de. Cartografias do cuidado de individuos com diabetes mellitus em situação de pobreza. 2011. 203 f. Tese (Doutorado) - Escola de Enfermagem, Universidade Federal do Rio Grande do Sul, Porto Alegre, 2011.

TONEZER, C. Idosos rurais de Santana da Boa Vista - Rio Grande do Sul: efeitos da cobertura previdenciária. 2009. 167 f. Dissertação (Mestrado em Desenvolvimento Rural) - Faculdade de Economia, Universidade Federal do Rio Grande do Sul, Porto Alegre, 2009.

WALACHAI: um Brasil ainda desconhecido. Direção: Rejane Zilles. [S.l.]: Okna Produçóes; Zilles Produçôes Culturais, 2009. 1 DVD (84 min.), son., color.

ZOBOLI, E. L. C.; JUNGES, J. R.. Justiça sanitária como tema de reflexão para a bioética clínica. In: SIQUEIRA, J. E. de; ZOBOLI, E.; SANCHES, M.; PESSINI, L. (Org.). Bioética clínica: memórias do XI Congresso Brasileiro de Bioética, III Congresso Brasileiro de Bioética Clínica e III Conferência Internacional sobre o Ensino da Ética. Brasília: CFM/SBB, 2016, p. 55-72.

\section{Notas}

${ }^{1}$ A. B. participou da concepção, geração, análise e discussão das informações, e da redação, formatação e revisão do artigo. T. E. Gerhardt participou da concepção, discussão, redação e revisão do manuscrito. 


\section{Abstract}

Experiences of recognition and care actions in the daily life of rural elderly men

As they age, men face particular challenges in dealing with a duality of demands: the social and the health ones. In this experience, social relations contribute to generate situations of care or suffering. This is a qualitative research carried out in a rural community of a small municipality of Vale da Luz, Rio Grande do Sul state, Brazil. Information was produced between December 2015 to September 2016, through daily journal writing and open interviews with 10 chronically ill elderly men. The analytical process was based on Scott's gender and Honneth's recognition concepts. It was evidenced that recognition by love acts as a modulator of biological care in chronic conditions, but it generates suffering by marking invulnerability and partial self-sufficiency in aging. In the area of law, recognition is established by retirement and access to health services. Identities - colonial, working, and German - are categories of esteem, and foster solidarity, especially in situations of illness. Relationships were allied in care, but by distancing men from the masculinity model or by disparaging choices, they caused suffering.

> Keywords: health of the elderly; men's health rural; population health; community health. 